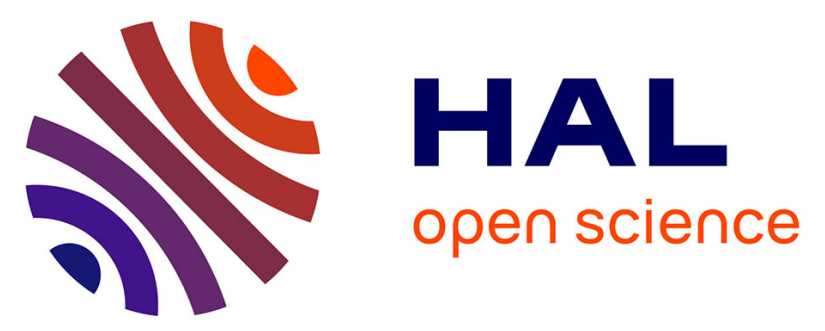

\title{
Fast mid-infrared spectroscopy of gases: Measurement method during a $\mathrm{H} 2 / \mathrm{O} 2$ deflagration
}

\author{
Marie Dabos, Khanh-Hung Tran, Nicolas Lecysyn, Gerard Baudin, Marc \\ Genetier, Isabelle Ranc-Darbord, Bruno Serio, Antoine Osmont
}

\section{To cite this version:}

Marie Dabos, Khanh-Hung Tran, Nicolas Lecysyn, Gerard Baudin, Marc Genetier, et al.. Fast midinfrared spectroscopy of gases: Measurement method during a $\mathrm{H} 2 / \mathrm{O} 2$ deflagration. AIP Conference Proceedings, 2020, SHOCK COMPRESSION OF CONDENSED MATTER - 2019: Proceedings of the Conference of the American Physical Society Topical Group on Shock Compression of Condensed Matter, 2272 (1), pp.060007. 10.1063/12.0000854 . hal-03174380

\section{HAL Id: hal-03174380 \\ https://hal.parisnanterre.fr/hal-03174380}

Submitted on 23 Mar 2021

HAL is a multi-disciplinary open access archive for the deposit and dissemination of scientific research documents, whether they are published or not. The documents may come from teaching and research institutions in France or abroad, or from public or private research centers.
L'archive ouverte pluridisciplinaire HAL, est destinée au dépôt et à la diffusion de documents scientifiques de niveau recherche, publiés ou non, émanant des établissements d'enseignement et de recherche français ou étrangers, des laboratoires publics ou privés. 


\section{Fast mid-infrared spectroscopy of gases: Measurement method during a $\mathrm{H}_{2} / \mathrm{O}_{2}$ deflagration}

Cite as: AIP Conference Proceedings 2272, 060007 (2020); https://doi.org/10.1063/12.0000854 Published Online: 04 November 2020

Marie Dabos, Khanh-Hung Tran, Nicolas Lecysyn, Gérard Baudin, Marc Genetier, Isabelle Ranc-Darbord, Bruno Serio, and Antoine Osmont

View Online

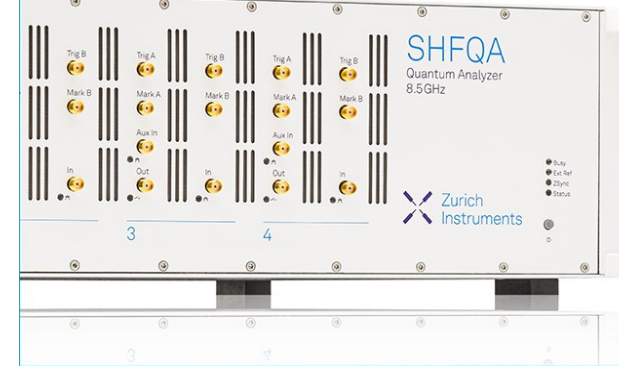

\section{Learn how to perform}

the readout of up

to 64 qubits in parallel

With the next generation

Register now

of quantum analyzers

on November 17th 


\title{
Fast Mid-Infrared Spectroscopy of Gases: Measurement Method during a $\mathrm{H}_{2} / \mathrm{O}_{2}$ Deflagration
}

\author{
Marie Dabos, ${ }^{1,2, \text { a) }}$ Khanh-Hung Tran, ${ }^{2}$ Nicolas Lecysyn, ${ }^{1}$ Gérard Baudin, ${ }^{1}$ Marc \\ Genetier, ${ }^{1}$ Isabelle Ranc-Darbord, ${ }^{2}$ Bruno Serio, ${ }^{2}$ and Antoine Osmont ${ }^{1}$ \\ ${ }^{1)}$ CEA, DAM, CEA-Gramat, F- 46500 Gramat, France \\ ${ }^{2)}$ LEME, Paris Nanterre University, 50 rue de Sèvres, 92410 Ville d'Avray, France \\ a)Corresponding author: marie.dabos@parisnanterre.fr
}

\begin{abstract}
To study detonation products of condensed matter in the post-combustion phase, a preliminary work is carried out on deflagrations. The study of the radiative properties of molecules during this fast phenomenon is not simple in the mid-infrared range. As the flame front of a $\mathrm{H}_{2} / \mathrm{O}_{2} / \mathrm{N}_{2} / \mathrm{CO}_{2}$ gas mixtures spreads in a few tens of meters per second, a fast infrared detection system is required. Besides, there are no calibrating sources in that spectral range for the intensity and spectral position calibration. The important feature of the experimental set-up presented is the record of high-resolution spectra at high frequency, up to 10 $\mathrm{kHz}$. The set-up is composed of a deflagration chamber with optical accesses. The pressure evolution is measured by a high speed piezoelectric sensor. The ignition is synchronized with the camera trigger. The radiation is focused into a monochromator and at its exit slit, a camera records the spectra in real time. The spectral intensity is calibrated using a blackbody. The correspondence between the spatial position of a pixel and the wavelength is fitted using an original method based on the application of a third degree polynomial, taking into account optical aberrations. The resulting spectra can be used to determine the temperature and the emissivity of gases.
\end{abstract}

\section{INTRODUCTION}

The states reached in the post-combustion phase of an aerial detonation can be recreated with deflagrations. The objective of this work is to present an experimental method to study the radiative properties of gas products, in the midinfrared wavelength range. The idea is to study the evolution of their emission by spectroscopy. The main challenge with such study, is that a deflagration of a $\mathrm{H}_{2} / \mathrm{O}_{2} / \mathrm{N}_{2} / \mathrm{CO}_{2}$ gas mixture is a fast phenomenom regarding the existing infrared sensors: a typical deflagration generated in the combustion chamber lasts a few tens of milliseconds. In order to have at least one image per millisecond, the spectrometer would have to run at $1000 \mathrm{~Hz}$ minimum. Commercially available spectrometers do not run that fast, this is why an infrared camera is chosen to replace such detectors in the set-up of the study. Besides, unlike visible spectroscopy where mercury or sodium lamps can be used, there aren't any standard sources in the infrared range [1]. It is then difficult to know the exact wavelength positions. These challenges are overcome by calibrating the wavelength positions using an original method with a polynomial regression, which also takes into account a known spectra of gas and a correction of the optical abberrations, the intensity is calibrated using a black body.

To study the state of the gas mixtures, three different types of information are needed: the final temperature, the final pressure, and the evolution of the emissivity.

\section{THE EXPERIMENTAL SET-UP}

The set-up is composed of a cylindrical deflagration chamber, a spectroscope and an infrared camera (Figure 1) [2]. The deflagration chamber is $600 \mathrm{~mm}$ long and has an inside diameter of $150 \mathrm{~mm}$. It includes frontal and lateral optical accesses. It was designed to stand sudden variations of temperatures from $300 \mathrm{~K}$ to $3500 \mathrm{~K}$ and pressures up to $20 \mathrm{MPa}$. The evolution of the pressure is measured by a high speed piezoelectric sensor. Once the gas mixture is injected in the chamber, the ignition is initiated by a spark plug at one end. It is synchronized with the triggers of the camera and the pressure sensor. Opposite the spark plug, the radiation from the flame front comes out through a sapphire window, which diameter is $20 \mathrm{~mm}$ and width $5 \mathrm{~mm}$. A parabolic mirror focuses the radiation into the entry slit of the spectroscope. The spectroscope, a SOPRA UHRS 1150, is mounted into an Ebert-Fastie configuration. The diffraction grating inside is blazed at $1.6 \mu \mathrm{m}$ and with of 600 grooves $/ \mathrm{mm}$. It can be turned by a handle to select the central wavelength of the diffracted light beam. The incident beam from the entry slit is seperated in terms of wavelengths, and the image of the spectrum is formed at the exit slit of the spectroscope. The resolution of the

Shock Compression of Condensed Matter - 2019

AIP Conf. Proc. 2272, 060007-1-060007-5; https://doi.org/10.1063/12.0000854

Published by AIP Publishing. 978-0-7354-4000-5/\$30.00 


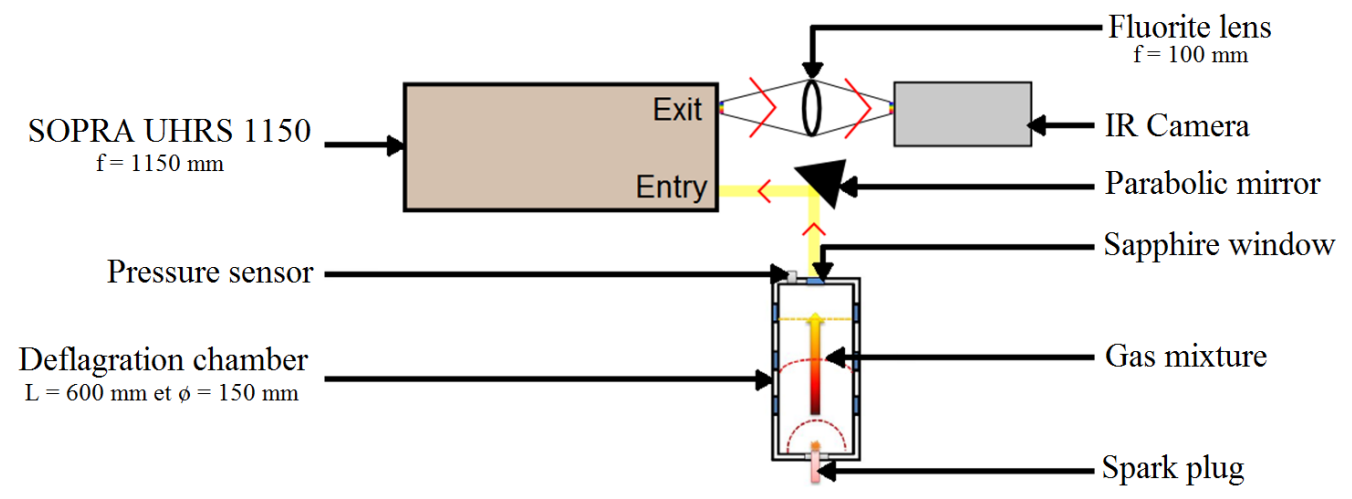

FIGURE 1. The experimental set-up

spectrum obtained is below one nanometer. The image is focused on the matrix of an infrared camera by a fluorite lens. When a flame front moves forward in the deflagration chamber, the evolution of the spectra is recorded in real time. The images recorded are usually limited to a certain region of interest on the matrix of the camera, in order to increase the sampling rate. A National Instruments acquisition card synchronizes the trigger signals and enables the numerical recording of the pressure.

An example of an image obtained is showed in Figure 2. The raw image of a spectrum, which shows emission lines as a function of the pixel position, has to be processed into a spectrum with the radiance level as a function of the wavelength.

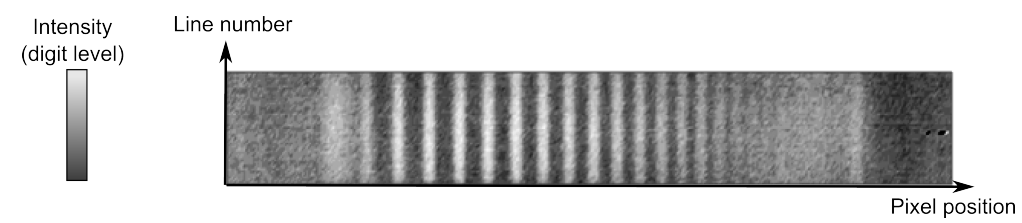

FIGURE 2. An example of a raw spectrum acquired: $\mathrm{CO}_{2}$ emission bands centered at $4.18 \mu \mathrm{m}$ from a butane flamme

\section{Temperature determination}

Hot gases absorb and emit an electromagnetic radiation which depends on their temperature. The emission or radiance of the molecules, follows Planck's law (1). $C_{1}$ and $C_{2}$ are Planck's constants, respectively equal to $1191.108 \mathrm{~W} \cdot \mu \mathrm{m}^{4} \cdot \mathrm{m}^{-2} \cdot \mathrm{sr}^{-1}$ and $14388 \mu \mathrm{m} \cdot \mathrm{K}$.

$$
L_{\lambda, T}^{0}=C_{1} \cdot \lambda^{-5} \frac{1}{\exp \left(\frac{C_{2}}{\lambda \cdot T}\right)-1}
$$

The temperature is determined from $\mathrm{CO}_{2}$ 's emission spectrum at its $v_{3}$ infrared band, centered at $4.2553 \mu \mathrm{m}$. The band has a fine structure caused by vibrational and rotational transitions. The region chosen to determine the temperature of the hot gas is at one of the band's end, which has the characteristic to present two lines from the fine structure that are called "headbands". These "headbands", located at $\lambda_{1}=4.1717 \mu \mathrm{m}$ and $\lambda_{2}=4.1928 \mu \mathrm{m}$, have been chosen for their strong thermometric effect [3]. In fact, their intensity is very sensitive to the molecule's temperature. This is due to the high accumulation of lines with close wavelengths. When the temperature rises, the population in high energy levels increases and the intensity of poorly excited lines decreases. At high temperatures and for a minimum concentration, $\mathrm{CO}_{2}$ behaves like a black body [3] and follows Planck's law. Therefore, from the measurement of $\mathrm{CO}_{2}$ 's radiance, the temperature is easily determined from Planck's law (1) when $\mathrm{CO}_{2}$ is brought to high temperatures. It is the case in gas deflagrations. The common temperatures obtained for $\mathrm{H}_{2} / \mathrm{O}_{2} / \mathrm{N}_{2} / \mathrm{CO}_{2}$ deflagrations are between $2500 \mathrm{~K}$ and $3500 \mathrm{~K}$. 


\section{PROCESSING SPECTRA}

The images obtained by the camera represent the intensity (digit level) as a function of the pixel position on the camera's matrix. To use the data measured, these images have to be processed into spectra with the radiance as a function of the wavelength position. Processing the spectrum images acquired by the camera results in 3 steps: improving of the signal to noise ratio, calibrating the position, which is done at the same time as correcting the distortion, and finally calibrating the intensity.

\section{Step 1: Signal/noise ratio improvement}

\section{Step 1.1: Reduction of the ambient $\mathrm{CO}_{2}$ absorption for temperature determination}

Temperature is determined through the measurement of $\mathrm{CO}_{2}$ 's radiance between $\lambda_{1}=4.1717 \mu \mathrm{m}$ and $\lambda_{2}=4.1928 \mu \mathrm{m}$. However, when the radiation from the deflagration chamber travels to the camera, the $\mathrm{CO}_{2}$ present in the optical path absorbs some of the radiation. An example is given in Figure 3, presenting the recorded image of a black body, which is supposed to be continuous. The $\mathrm{CO}_{2}$ absorption lines are clearly visible. To reduce the contribution of the ambient $\mathrm{CO}_{2}$ molecules, nitrogen is injected inside the spectroscope, as it is the place where the beam travels the greatest distance (the spectroscope's focal length is $1150 \mathrm{~mm}$ ). Even if the absorption lines did not completely vanish, the resulting image shows a great decrease in the absorption lines on the black body spectrum image (Figure 3).

\section{Step 1.2: Noise reduction}

To increase the signal to noise ratio, the spectrum images have to be corrected from three phenomena : the camera's electronic noise, the non-uniform response of the pixels against a same illumination input, and thermal noise.

The electronic noise is commonly corrected automatically by the camera. The second phenomenom is corrected by applying the non-uniformity correction (NUC), commonly present in the camera's software. Finally, for the thermal noise, a video of the dark is recorded after every deflagration, with the same acquisition parameters. The dark represents the signal measured when no deflagration occurs. The video recorded is substracted from the initial deflagration video. An example of a spectrum before and after these corrections is presented in Figure 4.

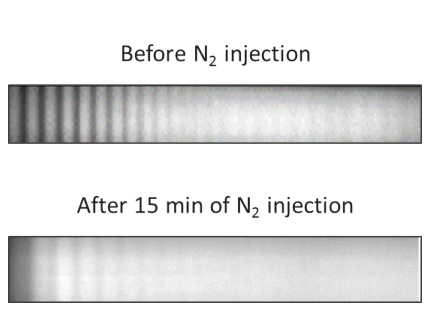

FIGURE 3. Black body spectrum between $4.17 \mu \mathrm{m}$ and $4.20 \mu \mathrm{m}$, before and after nitrogen injection in the spectroscope

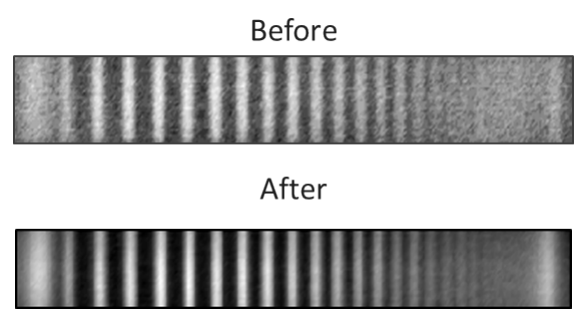

FIGURE 4. Corrected spectrum after noise reduction

\section{Step 1.3: Mean line calculation}

Finally, at each pixel position number, the mean intensity is calculated (Figure 5). From the image obtained, a spectrum can be plotted with the intensity as a function of the pixel position.

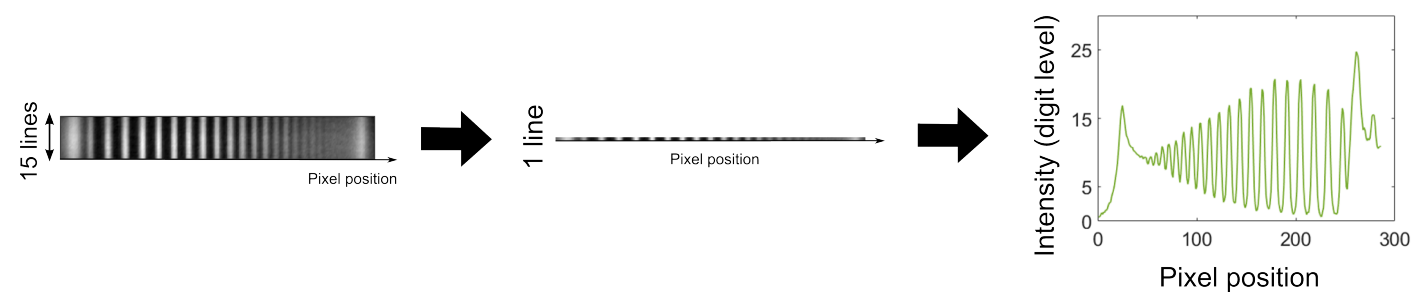

FIGURE 5. Mean line calculation from the image of $\mathrm{CO}_{2}$ emission bands centered at $4.18 \mu \mathrm{m}$ from a butane flamme 


\section{Step 2: Distortion correction and wavelength calibration}

The infrared range can be a challenging area to study since there are no calibrating sources, unlike the visible range where mercury lamps can be used for instance. The correspondence between the spatial position of a pixel and the wavelength is fitted using a method based on the application of a third degree polynomial, taking into account optical aberrations.

The different elements in the optical path (parabolic mirror, spectroscope and lens) cause a distorsion of the spectrum image projected on the camera's matrix. Because of this, the relation between the pixel position and the wavelength is not linear. It is quite a challenge in the infrared range. In this work, the distortion is corrected using a polynomial regression. Since the wavelength range studied stays the same when spectra are recorded during a deflagration, the wavelength calibration is done prior to the deflagration by recording a spectrum of known flame product in the same wavelength range. For instance, temperature studies are done in a range where $\mathrm{CO}_{2}$ radiates, so the calibration is done from the emission lines of $\mathrm{CO}_{2}$ produced by a flame. Besides, $\mathrm{CO}_{2}$ emission lines are well-known at atmospheric pressure, they can by calculated from HITRAN's database [4]. The spectrum recorded is compared to the theoretical spectrum: the pixel position of the identifiable lines are associated to the corresponding wavelengths. With these data, the polynomial regression is applied (2) to determine the A, B and C coefficients. Finally knowing the relation between the pixel position and the wavelength, the polynomial can be applied to all the spectra recorded during a deflagration. Figure 6 presents an example of a corrected spectrum of $\mathrm{CO}_{2}$ produced from a butane flame.

$$
\lambda_{\text {real }}=\lambda_{0}+A \cdot p+B \cdot p^{2}+C \cdot p^{3}
$$

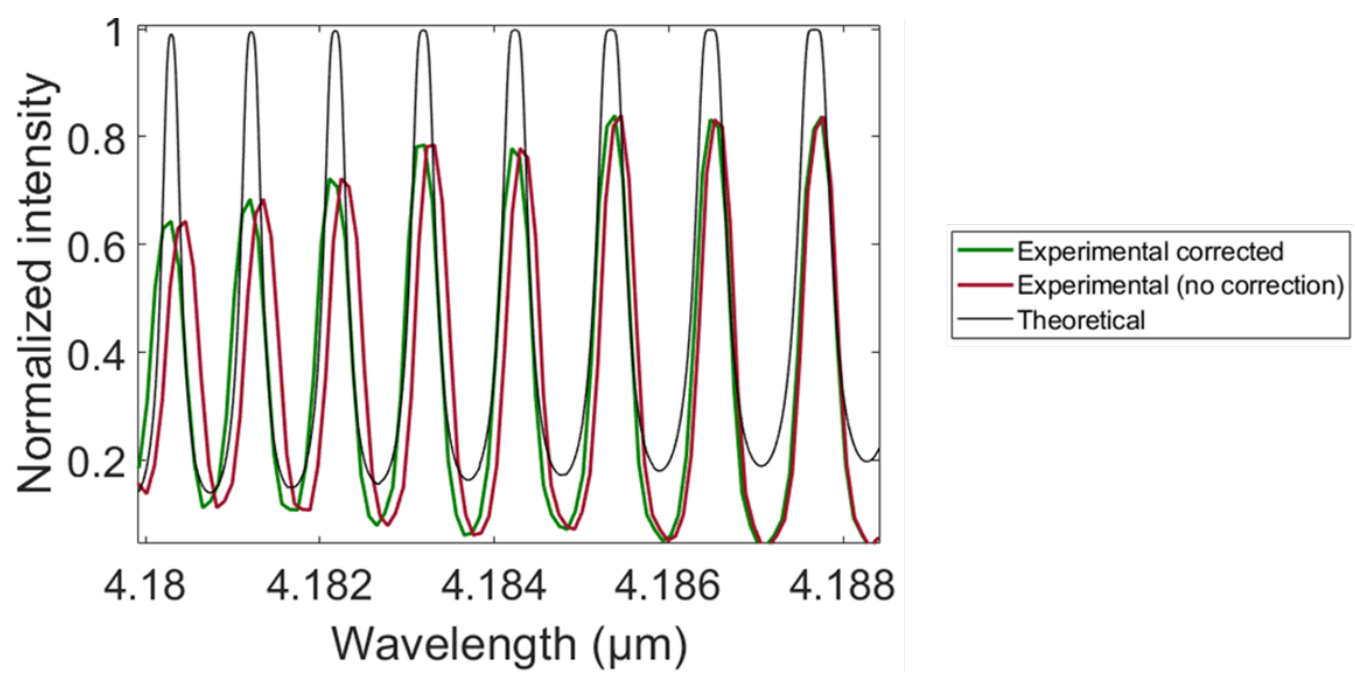

FIGURE 6. Example of a $\mathrm{CO}_{2}$ spectrum before and after the correction of the distortion

\section{Step 3: Intensity calibration}

The spectral intensity is calibrated using a blackbody in order to know the correspondence between the digit level and the radiance on the recorded spectra. The relation between the radiance $L_{\lambda, T}^{0}$ and the digit level $S_{\lambda, T}^{0}$ is given by (3). The apparatus function, $F_{\lambda}$, does not depend on the temperature. It is calculated by dividing the radiance of a black body, determined by Planck's law (1), by the experimental signal measured of a black body (Figure 7). The apparatus function can then be multiplied to the spectra recorded during a deflagration, to the correct radiance levels. An example of a corrected spectrum is given in Figure 7.

$$
L_{\lambda, T}^{0}=S_{\lambda, T}^{0} \cdot F_{\lambda}
$$



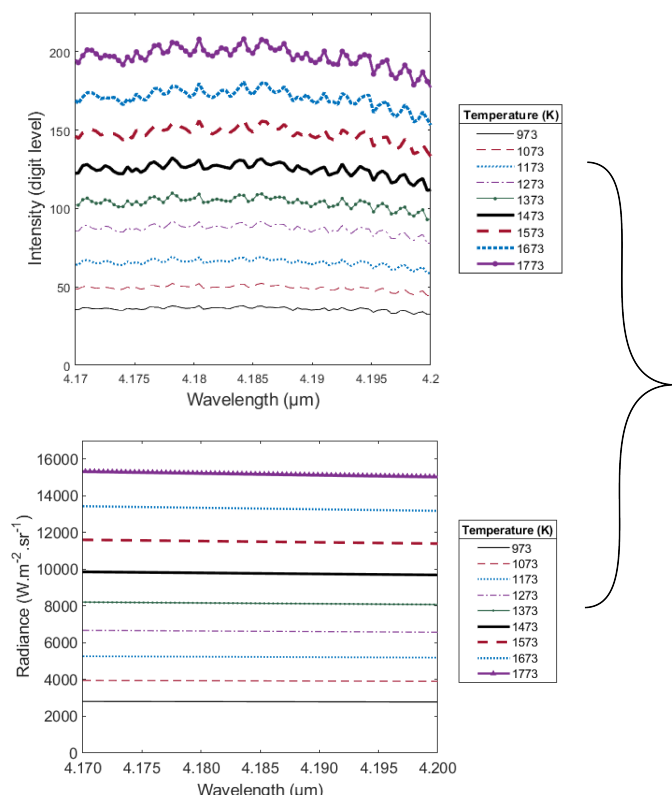

Application of the apparatus function on the spectrum

FIGURE 7. Apparatus function obtention

\section{CONCLUSION}

In the infrared range, spectra acquisition for phenomena like deflagrations requires the use of a high speed camera with a sampling rate above one kilohertz. In this work, an experimental set-up is suggested to record spectra during a deflagration. The usual calibration methods also have been reviewed, since there are no infrared calibrating sources. An original method is used to calibrate the wavelengths and correct the optical distorsions at the same time. The correct radiance level is determined with a black body. Using $\mathrm{CO}_{2}$ as tracer, it is possible to determine the final temperature by spectroscopy. The whole process presents how to obtain spectra from the images recorded by the camera. Spectra measurements presented here contribute to works to validate and improve thermochemical simulations by studying the radiative properties of gases.

\section{ACKNOWLEDGMENTS}

This research is financially supported by the French Ministry of the Armed Forces - Defense Innovation Agency, and the DGA.

\section{REFERENCES}

1. A. Pettersson, Investigations of infrared chemiluminescence emission from laboratory flames, Master's thesis, Lund Institue of Technologies (2004).

2. P. Chelin, C. Camy-Peyret, V. Pina, P. Alkhoury, and D. Davidenko, "Emission spectroscopy of hot water vapor from H2-air deflagrative combustion in a closed cylinder," Combustion and Flame 140, 319-331 (2005).

3. R. Conseil, D. Ramel, J. Lebedinsky, Y. Bailly, and P. Hervé, "Determination of hot gas temperature profiles by IR spectroscopy," in 15th International Symposium on Flow Visualization (2012).

4. L. Rothman and et al, "The HITRAN 2012 molecular spectroscopic database," J. Quant. Spectrosc. and Rad. Transfer 130, 4-50 (2013). 